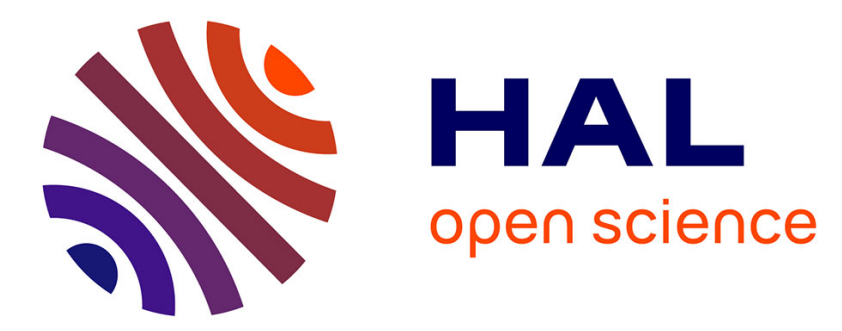

\title{
Modelling of non-consolidated oil shale semi-coke forward combustion: influence of carbon and calcium carbonate contents
}

Hossein Fadaei, Mohammed Sennoune, Sylvain Salvador, Alexandre Lapene,

Gérald Debenest

\section{To cite this version:}

Hossein Fadaei, Mohammed Sennoune, Sylvain Salvador, Alexandre Lapene, Gérald Debenest. Modelling of non-consolidated oil shale semi-coke forward combustion: influence of carbon and calcium carbonate contents. Fuel, 2012, vol. 95, pp. 197-205. 10.1016/j.fuel.2011.11.066 . hal-00963632

\section{HAL Id: hal-00963632 \\ https://hal.science/hal-00963632}

Submitted on 21 Mar 2014

HAL is a multi-disciplinary open access archive for the deposit and dissemination of scientific research documents, whether they are published or not. The documents may come from teaching and research institutions in France or abroad, or from public or private research centers.
L'archive ouverte pluridisciplinaire HAL, est destinée au dépôt et à la diffusion de documents scientifiques de niveau recherche, publiés ou non, émanant des établissements d'enseignement et de recherche français ou étrangers, des laboratoires publics ou privés. 


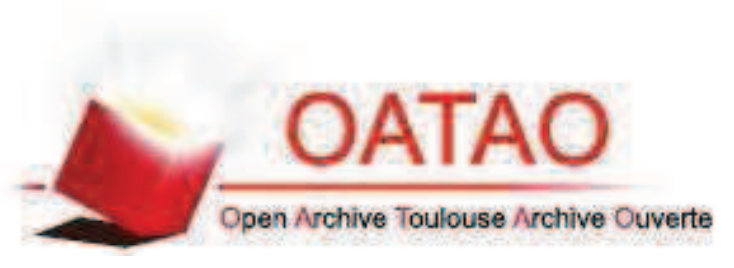

\section{Open Archive Toulouse Archive Ouverte (OATAO)}

OATAO is an open access repository that collects the work of Toulouse researchers and makes it freely available over the web where possible.

This is an author-deposited version published in: http://oatao.univ-toulouse.fr/ Eprints ID: 10517

To link to this article : DOI:10.1016/j.fuel.2011.11.066

URL : http://www.sciencedirect.com/science/article/pii/S0016236111007800\#

\section{To cite this version:}

Fadaei, Hossein and Sennoune, Mohammed and Salvador, Sylvain and lapene, alexandre and Debenest, Gérald Modelling of non-consolidated oil shale semicoke forward combustion: influence of carbon and calcium carbonate contents. (2012) Fuel, vol. 95. pp. 197-205. ISSN 0016-2361 


\title{
Modelling of non-consolidated oil shale semi-coke forward combustion: Influence of carbon and calcium carbonate contents
}

\author{
Hossein Fadaei $^{\mathrm{a}, *}$, Mohammed Sennoune $^{\mathrm{a}}$, Sylvain Salvador ${ }^{\mathrm{a}}$, Alexandre Lapene ${ }^{\mathrm{b}}$, Gerald Debenest $^{\mathrm{c}}$ \\ ${ }^{a}$ Université de Toulouse, Mines Albi, RAPSODEE, FRE 3213, Campus Jarlard, Albi F-81013, France \\ ${ }^{\mathrm{b}}$ Stanford University, ERE Department, 367 Panama St., Stanford, CA 94305, USA \\ ${ }^{\mathrm{C}}$ Université de Toulouse, CNRS, IMFT, Allée Camille Soula, F-31400 Toulouse, France
}

\begin{abstract}
A B S T R A C T
A one dimensional (1-D) numerical model to describe forward filtration combustion in a porous bed is proposed. The numerical model is based on mass and momentum conservation law (generalized Darcy's law). We assume local thermal equilibrium between gas and solid phases. The effect of carbon and calcium carbonate content on the propagation of the high temperature combustion front has been investigated. A simple carbon oxidation reaction, producing $\mathrm{CO}$ and $\mathrm{CO}_{2}$, describes the combustion. We found that increasing the carbon content of the bed increases the peak temperature. However, the combustion front velocity versus carbon content does not show a monotone behaviour. The front velocity increases while carbon content increases up to a certain value and then decreases. Also, we observed that higher the temperature is, stronger the calcium carbonate decomposition is. Consequently, the calcium carbonate decomposition is closely linked to the peak temperature. Moreover, increasing the calcium carbonate content of the porous bed resulted a decrease of the peak temperature. These results as well as the composition of produced gases are consistent with the previous published experimental study. Results of this paper show that using a 1-D model with a simple reaction scheme for combustion and for calcium carbonate decomposition produces satisfactory results for simulation of filtration combustion process.
\end{abstract}

\section{Introduction}

The combustion process in porous media has been the subject of great interest because of its vast applications in different areas: environmental applications such as forest fire or waste incineration and cigarette burning, production of new materials such as synthesized porous media based on metals or ceramics, porous burners in which a mixture of a fuel and an oxidizer burn, regeneration of some catalytic beds in the refineries and many other applications [1-3].

Generally, combustion in porous media is known as filtration combustion, where delivery of reactants through the pores to the reaction site is an important aspect of the combustion process [4]. Smoldering and SHS (self-propagating high temperature synthesis) are two important categories of the filtration combustion. As defined by Ohlemiller [2] "Smouldering is a slow, low-temperature, flameless form of combustion, sustained by the heat evolved when oxygen directly attacks the surface of a condensed-phase fuel". In this process, two combustion configurations can be distinguished: opposed and forward propagation. These situations are occurred depending to the direction in which the reaction front(s) propagates relative to the air (oxidizer) flow. Forward smoulder happens

\footnotetext{
* Corresponding author. Tel.: +1 4167041288

E-mail address: hfadaei@utoronto.ca (H. Fadaei).
}

when reaction front propagates in the same direction as the oxidizer flow while in the opposed smoulder, these directions are opposite.

In a pioneering work Aldushin et al. [5] studied the one dimensional combustion wave propagation in a porous medium. Based on the asymptotic method, they determined the structure of the solution. A so-called reaction leading structure occurs when the velocity of the combustion front (reaction front) exceeds that of the heat transfer layer, while a so called reaction trailing structure is obtained when the combustion front is slower than the heat transfer front. Many other researchers have been involved in the development of this method. Most of their works are based on the macroscopic (averaged) approach for presenting the transport equations. The work of Ohlemiller [2], Schult et al. [6] and Oliveira and Kaviany [3] are some important references. Some other works also have been done at grain (pore) scale where the local (microscale) transport equations are considered (see Debenest [7]). Even if the results can exhibit behaviours and pertinent non-dimensional numbers, it is not possible to use that approach to study the combustion wave propagation at the metric scale. However, it is possible to determine a complete thermochemical data bank (see Elayeb [8]).

As far as quantitative modelling of a smoldering front is concerned, this has been for a long time and still remains a challenge 


\begin{tabular}{|c|c|c|c|}
\hline \multicolumn{2}{|c|}{ Physical symbols } & $R$ & perfect gas constant $\left(8.32 \mathrm{~J} \mathrm{~K}^{-1} \mathrm{~mol}^{-1}\right)$ \\
\hline$R_{\mathrm{g}, \mathrm{k}}$ & generation or sink of gas in species $\mathrm{k}\left(\mathrm{kg} \mathrm{m}^{-3} \mathrm{~s}^{-1}\right)$ & $v$ & velocity $\left(\mathrm{m} \mathrm{s}^{-1}\right)$ \\
\hline$\dot{R}^{\text {sin }}$ & mass generation $\left(\mathrm{kg} \mathrm{m}^{-3} \mathrm{~s}^{-1}\right)$ & Y & mass fraction $(-)$ \\
\hline$A_{0}$ & pre-exponential factor $\left(\mathrm{s}^{-1}\right)$ & & \\
\hline$E_{\mathrm{ac}}$ & activation energy $\left(\mathrm{J} \mathrm{mol}^{-1}\right)$ & $\mu$ & dynamic viscosity $\left(\mathrm{kg} \mathrm{s}^{-1} \mathrm{~m}^{-1}\right)$ \\
\hline fr CO & fraction of FC oxidized into $\mathrm{CO}(-)$ & $\rho$ & volumetric mass $\left(\mathrm{kg} \mathrm{m}^{-3}\right)$ \\
\hline$h$ & $\begin{array}{l}\text { heat transfer coefficient between medium and cell walls } \\
\left(\mathrm{W} \mathrm{m} \mathrm{m}^{-2} \mathrm{~K}^{-1}\right)\end{array}$ & $\varepsilon$ & porosity (-) \\
\hline$K$ & permeability $\left(\mathrm{m}^{2}\right)$ & \multicolumn{2}{|c|}{ Subscript } \\
\hline
\end{tabular}

to science. At first, since two waves are propagating and at different velocities, the solution cannot be steady but is transient. The difficulty mainly comes from the fact that numerous thermal, flow and chemical phenomena occur simultaneously and are coupled. Their quantitative description requires the knowledge of physical, thermal and chemical properties of the reactive porous medium. These properties are difficult to determine in the laboratory; some of them depend on the temperature, and change as chemical reactions occur. Among them, the stoichiometric and kinetic parameters for the chemical reactions remain the more challenging to determine, and remain hard points in the modelling approach [2]. The main reaction to propagate a smoldering front is carbon oxidation. As will be discussed further, this reaction leads both to $\mathrm{CO}$ and $\mathrm{CO}_{2}$ production. The prediction of the repartition between these two species remains difficult. Nevertheless, it impacts both on the stoichiometry and on the exothermicity of the reaction [9].

Another difficulty encountered is to establish reliable sets of experimental data to calibrate and validate the models. The high temperature levels induce heat losses at the cell walls, making a pure 1-D situation difficult to maintain $[9,10]$. Moreover, most of the solid fuels will undergo geometrical shrinkage at the passage of the front, creating bypasses to air circulation through the medium.

Altun et al. [11] defined oil shale as a sedimentary rock that contains an organic matter embedded in a mineral matrix. The organic matter may devolatilize at temperature increase $\left(\sim 220^{\circ} \mathrm{C}\right)$ into heavy oil, gaseous fractions and a carbonaceous residue called fixed carbon. The obtained solid that contains fixed carbon and the inorganic minerals of the original oil shale, is called semicoke.

Oil shale has been extensively studied in literature. Altun et al. [11] presented a review on the importance of oil shale reserves and oil shale potential and utilization in the world. A recent review of the oil shale and related reactions was done by Kok [12]. The environmental aspects of the oil shale industry has been reviewed by Kahru and Põllumaa [13]. Characterized the oil shale semi coke from different sources presented by Kulaots et al. [14]. The combustion technology of oil shales was presented by Ots [15].

Semi-coke is a side product of the oil recovery from oil shales during the retorting process.

Treatment of this product is indeed one of the important issues of this oil recovery process [10]. It presents a number of advantages making it a good candidate to smoldering experiments in the laboratory. It is a hard material that can be ground to the desired particle size, and the carbon is intimately distributed inside the grains. But its main advantage is that - contrarily to most of solid fuels - it undergoes only very little shrinkage during the combustion
$[10,16,17]$. This avoids radial shrinkage of the bed and preferential passage of at the walls of the cell during experiments, favouring a 1-D configuration.

It has been shown in [12] that during the high temperature smoldering in oil shale, the main reaction supplying energy to the front is fixed carbon oxidation, also called HTO. Furthermore, the devolatilization reaction heat is known to be very small and not to impact on the energy balance. Therefore, semicoke was used in this work. It does not contain oil, which avoids the devolatilization and LTO reactions. In the combustion study of the consolidated shale particles (cylinders of $5 \mathrm{~cm}$ diameter and 6.35 length), Manor et al. [18] carried out some thermo-gravimetric analysis of samples containing different organic matter under various operating conditions. It is found that the gasification reaction, carbon reaction with $\mathrm{CO}_{2}$ producing $\mathrm{CO}$, plays an important role in the combustion process under certain condition.

Using this material introduces another reaction at the passage of the hot front: decomposition of carbonates. This happens in most of oil recovery from oil shale applications. The very endothermic reaction will impact on the process both through the heat balance and by producing additional $\mathrm{CO}_{2}$.

During the past few years we have been dealing with the experimental study of oil recovery from oil shale [19] and semi-coke combustion $[9,10]$. In this work we present numerical study of the forward combustion of semi-coke material in a porous medium. The main aim is to evaluate the capacity of a numerical model involving simplified chemistry to predict the behaviour of a smouldering front in a medium containing carbon that oxidizes and carbonates that can decompose.

\section{Experimental study}

We present briefly the experimental set-up used by Sennoune et al. $[9,10]$ to study the semi-coke combustion. The oil shale used in the experimental part was from Timahdit formation of Atlas, Morroco. The semicoke was obtained from retorting of this oil shale; it was then mixed with sand and carbonate. An important set of repeated experiments has been established in which two parameters have been changed alternatively: (i) the amount of fixed carbon and (ii) the amount of carbonates in the medium. The semi-coke used for this work was prepared by retorting oil shale at pyrolysis temperature of $550{ }^{\circ} \mathrm{C}$ in a stainless-steel reactor externally heated by an electric rig furnace at atmospheric pressure and heating rate of $5^{\circ} \mathrm{C} \mathrm{min}^{-1}$. 


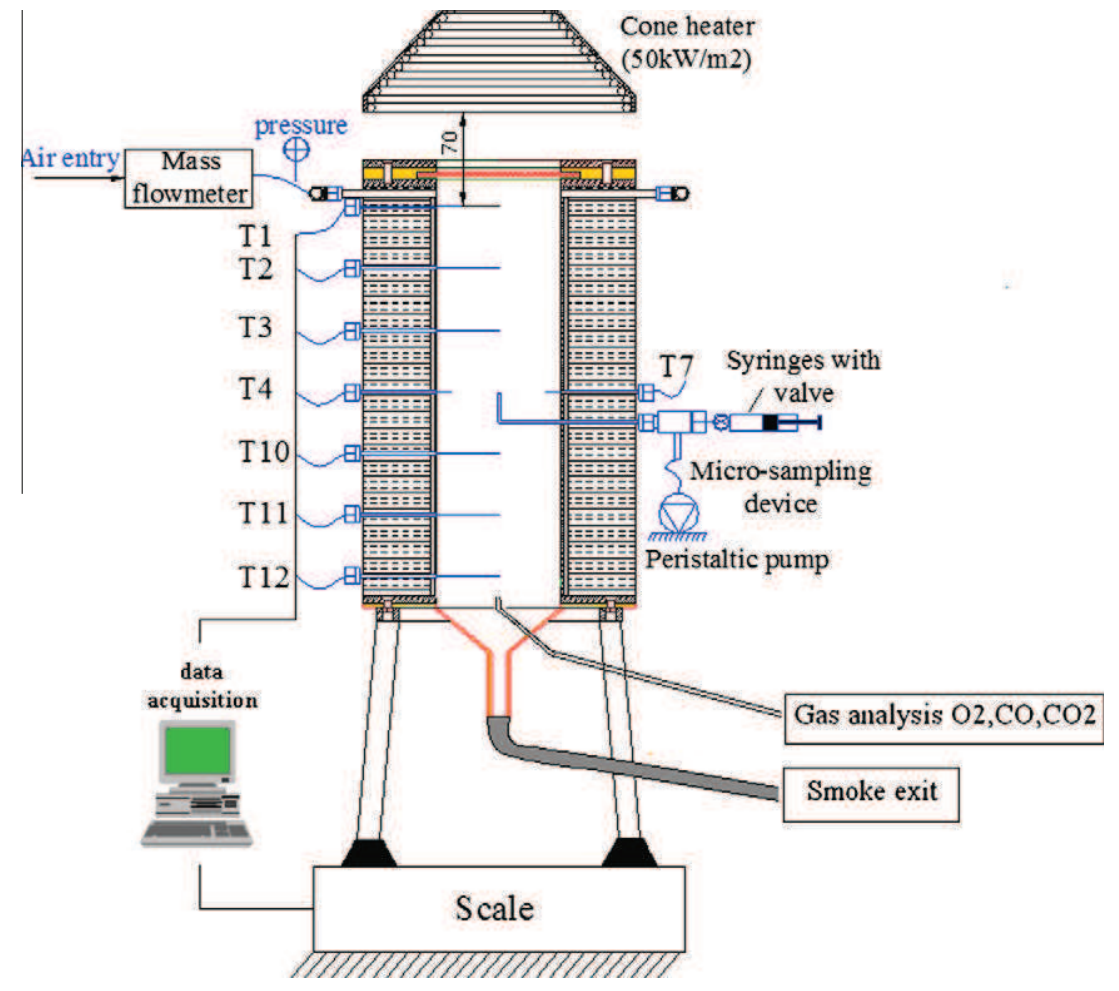

Fig. 1. Fixed bed reactor, with continuous gas sampling at the axis, presented in Sennoune et al. $[9,10]$.

The fixed carbon of a semicoke largely depends on the original oil shale; for the oil shale used in this work, the fixed carbon content was $6.95 \mathrm{wt} . \%$. This value was still too high for experiments and we were obliged to mix semicoke with $50 \%$ sand to keep acceptable front temperatures, i.e. lower than $1000^{\circ} \mathrm{C}$.

Downward filtration combustion tests were carried out in a fixed bed reactor as shown in Fig. 1. A detailed description of this reactor is given elsewhere [17]. Air is fed $\left(0.027 \mathrm{~kg} \mathrm{~m}^{-2} \mathrm{~s}^{-1}\right)$ into the top of a vertical cylinder of crushed semi-coke. Ignition also takes place at the top of the sample using a cone heater that irradiates the surface with $50 \mathrm{~kW} \mathrm{~m}^{-2}$ through a quartz window. During the experiment, temperatures in the bed were measured by six type-K thermocouples located along the axis of the cell at different heights $(T 1, T 2, T 3, T 10, T 11$ and $T 12)$. A crown of six thermocouples (T4-T9) makes it possible to measure the temperature $1 \mathrm{~cm}$ away from the cell walls over a horizontal cross section: this is particularly useful to reveal whether the smouldering front progresses as a horizontal surface. Composition of the gases was analyzed at the bed exit.

We compared our simulation results with results obtained in this experimental work. This will enable us to validate the sensitivity of the model to change in these two experimental parameters.

\section{Numerical model}

We choose to model the problem at the Darcy scale. At this scale, the governing equations are the upscaled version of "pore scale" equations. Mass and momentum conservation equations can only be written at the pore-scale where the continuum assumption is valid. Consequently, one needs to derive the transport equation at Darcy-scale from those at pore-scale. Considering all the complexities, both from geometrical and process point of view, Darcy-scale equations, here, are also called "averaged equations". They contain some simplifications and constraints [20]. This is, indeed, the case in most of the simulation tools in chemical and petroleum engineering domains.
The numerical model used in this study was developed in our laboratory [21]. Here, we present the basic characteristics of this model. The model consists of a coupled heat and mass transfer equation system that can handle combustion as well as carbonate decomposition reactions. Details of the governing equations are presented later. This model is designed to treat one and two dimensional problems. There are mainly two phases in our problem, gas and solid with the following compositions:

- Solid phase: fixed carbon, $\mathrm{CaCO}_{3}$, inert material;

- Fluid phase: gases $\mathrm{N}_{2}, \mathrm{O}_{2}, \mathrm{CO}, \mathrm{CO}_{2}$;

Reactions take place between gas and solid phase, such as fixed carbon combustion and also in the solid phase as carbonate decomposition.

Many smoulder reaction schemes have two steps. The solid fuel decomposes through endothermic pyrolysis, producing solid char and gaseous products. Then, the char oxidizes, usually during a highly exothermic reaction in which it is converted to gaseous product and ash.

The endothermic pyrolysis reaction is thought to have little impact on the structure of the solution [6]. Here, we assumed that the combustion of fixed carbon does not leave any ash and it totally converts to gaseous product. We are aware that coke combustion by itself is not a single reaction. The complex multi-step combustion reactions $[7,22]$ are simplified here as a one step reaction model.

Fixed carbon + Oxygen $\rightarrow \mathrm{CO}_{2}+\mathrm{CO}+$ Heat

The objective of this work is to check the validity of a simple one reaction model.

The so called "carbonate" matter in the solid phase is not a pure substance but at least contains calcium and lesser amount of magnesium carbonates. For the sake of simplicity, we assumed that the calcium carbonate is dominant. Thus, the following decomposition reaction is defined in the model as; 
Calcium carbonate $\left(\mathrm{CaCO}_{3}\right)+$ Heat $\rightarrow$ Calcium oxide $(\mathrm{CaO})+\mathrm{CO}_{2}$

We have not considered the possible presence of the gasification reaction as reported by Manor et al. [18] in the study of consolidated shale particles. However the present work deals with the non-consolidated porous media, but in a more detailed reaction study one may include this aspect in the analysis especially for rich shales and under the condition where the carbonate decomposition takes place. Fig. 2 shows the schematic of the model used for simulation of different cases.

\subsection{Governing equations, initial and boundary conditions}

Assuming a one-dimension problem, the governing equations are presented here:

\subsubsection{Mass conservation}

Total mass conservation equation of the gas phase is represented by the following equation in the model.

$\varepsilon_{\mathrm{g}} \frac{\partial\left(\rho_{\mathrm{g}}\right)}{\partial t}+\frac{\partial\left(\rho_{\mathrm{g}} v_{\mathrm{g}}\right)}{\partial x}=\dot{R}_{\mathrm{g}}$

It is important to note that the gas phase is considered as an ideal gas.

$$
P_{\mathrm{g}}=\rho_{\mathrm{g}} \frac{R T_{\mathrm{g}}}{\bar{M}_{\mathrm{g}}}
$$

Mass conservation equation of each specie is expressed as:

$\varepsilon_{\mathrm{g}} \frac{\partial\left(\rho_{\mathrm{g}} Y_{\mathrm{g}}\right)}{\partial t}+\frac{\partial\left(v_{\mathrm{g}} \rho_{\mathrm{g}} Y_{\mathrm{g}}\right)}{\partial x}=\frac{\partial}{\partial x}\left(\rho_{\mathrm{g}} D_{\mathrm{g}}^{*} \frac{\partial\left(Y_{\mathrm{g}}\right)}{\partial x}\right)+\dot{R}_{\mathrm{g}, \mathrm{k}}$

For solid phase, the conservation equation becomes:

$$
\left(1-\varepsilon_{\mathrm{g}}\right) \frac{\partial\left(\rho_{s}\right)}{\partial t}=\dot{R}_{s}
$$

Reaction rates are considered to be Arrhenius type. The combustion reaction rate depend on the fuel (fixed carbon) concentration and the oxygen concentration.

$\dot{R}_{\mathrm{i}}=A_{0} \exp \left(\frac{-E_{\mathrm{ac}}}{R T}\right)[\rho]_{\mathrm{c}}^{m}[\rho]_{\mathrm{O} 2}^{n}$

In this work $m$ and $n$ are considered to be equal to one.

Carbonate decomposition reaction is described through a single reaction that only involves calcium carbonate concentration.

$\dot{R}_{\mathrm{i}}=A_{0} \exp \left(\frac{-E_{\mathrm{ac}}}{R T}\right)[\rho]_{\mathrm{CaC} 03}^{m}$

In this equation, $m$ is equal to one. The reality is much more complex. Indeed, the total pressure of $\mathrm{CO}_{2}$ is known to impact on the reactions kinetics. Small increases in it lead to slowing down of the reaction. If this reaction is still increased and overpasses an equilibrium pressure, $\mathrm{CaCO}_{3}$ decomposition will stop and a reverse reaction, $\mathrm{CaO}$ re-carbonation to $\mathrm{CaCO}_{3}$ will take place [23].

Again it is one aim of this work to evaluate how accurately the $\mathrm{CaCO}_{3}$ decomposition progress can be described from a simplified reaction scheme and simplified kinetic model.

\subsubsection{Energy conservation}

Local thermal equilibrium [24] is assumed between solid and gas phases. Thus, heat transfer is represented by a one-equation model. Following conservation equation presents heat transfer by conduction, convection and heat generation due to chemical reactions.

$\left(\rho C_{\mathrm{P}}\right)_{\mathrm{t}} \frac{\partial T}{\partial t}+\left(\rho C_{\mathrm{P}}\right)_{\mathrm{P}} v_{\mathrm{g}} \frac{\partial T}{\partial x}=\frac{\partial}{\partial x}\left(\lambda^{*} \frac{\partial T}{\partial x}\right)+\dot{Q}$

\subsubsection{Momentum conservation}

It is assumed that the Darcy law, in its general form, is valid in this problem. The porous medium is considered to be isotropic, thus the absolute permeability is constant. The porosity and permeability of the bed are respectively measured as 50\% and 1 Darcy. Experimental results $[9,10]$ showed that pressure drop across the porous bed is small, thus we consider that the permeability value which is a rough estimate has no impact on the solution. Gravity effect is neglected. Finally, Darcy velocity for gas phase is defined as:

$v_{\mathrm{g}}=\frac{-K}{\mu_{\mathrm{g}}} \frac{\partial P_{\mathrm{g}}}{\partial x}$

\subsubsection{Initial and boundary conditions}

The porous space of the media is filled initially with air (21 wt.\% oxygen).

$$
\begin{aligned}
& T=0 ; \quad \forall x, Y_{\mathrm{O} 2}=Y_{\mathrm{O}, \mathrm{Air}} \\
& t>0 ; \quad @ x=0, Y_{\mathrm{O} 2}=Y_{\mathrm{O} 2, \mathrm{Air}} \\
& t>0 ; \quad @ x=0, v_{\mathrm{g}} \rho_{\mathrm{g}}=q_{\text {injection }} \\
& t>0 ; \quad @ x=L, P=P_{\text {out }}
\end{aligned}
$$


The system is initially at ambient temperature.

$t=0 ; \quad \forall x, T=T_{\text {ambient }}$

There are heat losses around the porous bed. We considered these heat losses according to the following boundary condition.

$t>0 ; \quad$ losses $=h\left(T-T_{\text {ambient }}\right)$

Because we have considered the half of the geometry in our model, thus the other boundary condition, for energy conservation, which correspond to the middle of the model (in axial direction) is the no-flow boundary.

$t>0 ; \quad \lambda^{*} \frac{\partial T}{\partial y}=0$

Boundary condition at bed surface during ignition:

$T_{\text {ignition }}>t ; \quad-\left.\lambda^{*} \frac{\partial T}{\partial x}\right|_{x=0}=q_{\text {radiation }}$

\subsection{Reaction stoichiometry and kinetics}

In this study we assumed that fixed carbon combustion produces $\mathrm{CO}_{2}$ and $\mathrm{CO}$ according to the following reaction.

Fixed carbon $+(1-f r) / 2$ Oxygen $\rightarrow(1-f r) \mathrm{CO}_{2}+(f r) \mathrm{CO}+$ Heat

The stoichiometry of this reaction depends to the "fr" value that was determined based on experimental results [10]. The " $f r$ " is the mass fraction of fixed carbon converted to CO.

For combustion reaction kinetics, we have taken activation energy from literature. For this parameter a range of values is presented (see the review made in Elayeb [22]) which is between 120 and $200 \mathrm{~kJ} \mathrm{~mol}^{-1}$. In another study, Ots [15] reported the activation energy for oil shale semicoke combustion to be around $100 \mathrm{~kJ} / \mathrm{kmol}$.

Smith et al. [25] carried out coal combustion experiments in the temperature range $25-900{ }^{\circ} \mathrm{C}$ using air at atmospheric pressure in a derivative thermo-gravimetry analysis system. Sixty-six coals with high vitrinite and low inorganic contents were examined as part of a coal characterization program. Calculated apparent activation energies were of the correct orders of magnitude to describe combustion regions corresponding to chemical-reaction-controlled as well as diffusion-controlled processes. Smith et al. [25] proposed a value for activation energy equal to $179.4 \mathrm{~kJ} \mathrm{~mol}^{-1}$ as an average value. We started with this value and finally found that with our model, an activation energy equal to $170 \mathrm{~kJ} \mathrm{~mol}^{-1}$ can produce accurate results. The pre-exponential factor was then adjusted based on the above mentioned activation energy.

For carbonate decomposition reaction, the activation energy found in literature [26] was ranging from 110 to $260 \mathrm{~kJ} \mathrm{~mol}^{-1}$. The reported activation energy values were obtained under the argon atmosphere which suggests that the corresponding values under the semicoke combustion flue gas atmosphere may be slightly different. We used the activation energy equal to $170 \mathrm{~kJ} \mathrm{~mol}^{-1}$ in our simulations. The pre-exponential factors used for the combustion and carbonate decomposition reactions are $2.5 \times 10^{10}\left(\mathrm{~Pa} \mathrm{~s}^{-1}\right)$ and $2.5 \times 10^{7}\left(\mathrm{~s}^{-1}\right)$ respectively.

\subsection{Solution method}

The above mentioned conservation equations and boundary conditions are discretized using the finite volume method based on a regular Cartesian mesh system. The convective transport term is discretized using upwind scheme and the second order scheme was used for diffusion term. We used a fully implicit approach for time discretization. The resulted equation system is solved by using a Newton-Raphson method. Primary variables were the pressure, temperature, global mole fractions of solid and gas phases.

\subsection{Grid sensitivity}

A sensitivity grid study based on the peak temperature has been performed. We conclude that 120 grid blocks are enough to reach the numerical convergence. Fig. 3 shows the results of this study. In this figure the maximum temperature versus time is plotted. We show that calculated temperatures for 240 and 120 grid blocks are pretty similar.

\subsection{Treatment of heat losses}

In order to mimic experimental constraints, heat losses are taken into account in the model. In this experiment, heat losses mainly occur because of conductive heat transfers through the wall and insulation, followed by convection around the cell.

The 1-D approach does not allow to reliably model all these phenomena. Then, we use a global heat losses coefficient.

When filtration combustion mode is reaction leading, most of the heat is accumulated behind the combustion front. Thus, the slope of the temperature profile versus distance behind the front is the combined result of the energy accumulation by the solid phase, advected heat and heat losses. We decided to adjust the heat losses coefficient to obtain the same slope for temperature profile behind the combustion front. Fig. 4 shows a typical temperature profile obtained in the simulation with an adjusted heat losses coefficient in comparison with experimental temperature and a simulated case with zero heat loss.

Results indicate that the heat loss model introduced in this study significantly improved the model predictability by reproducing the temperature profile ahead and behind the combustion front in a satisfactory manner as it is observed in the experiment. Small discrepancy exists for the combustion zone temperature around peak temperature value which will be discussed later.

\section{Results and discussion}

\subsection{Parameter fitting strategy}

We first adjusted model parameters (activation energies and pre-exponential factors) for the reference case (presented below) and then used them in all other cases. The parameters had then to be re-adjusted until the best average match was obtained considering all experiments together. Finally, one single set of parameters was used to simulate all the experiments. We used the peak temperature, the temperature profile versus distance, combustion

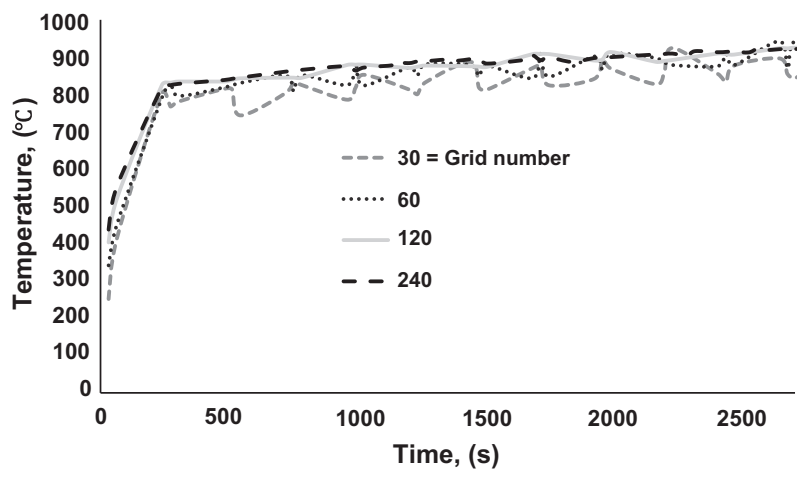

Fig. 3. Grid sensitivity test show that 120 number of grid is necessary in order the results to be independent of the grid size. 


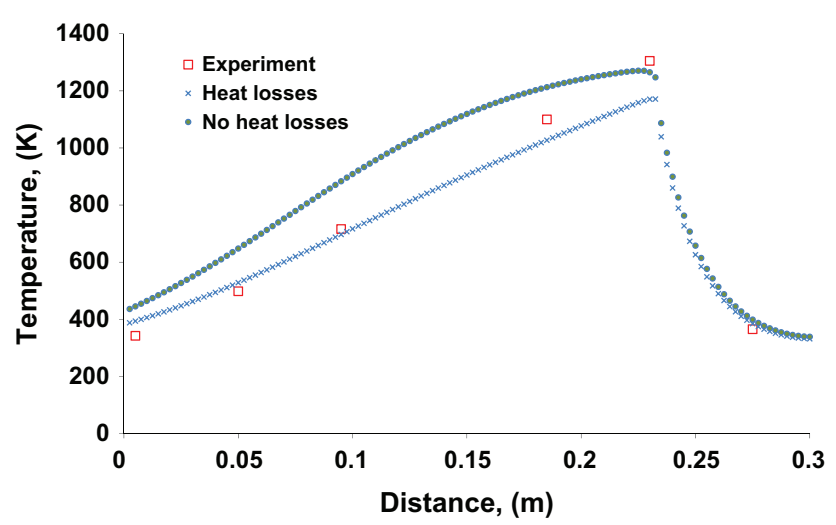

Fig. 4. Temperature profile versus distance, experimental results and simulation results with and without heat losses.

front velocity and the percentage of carbonate decomposition as matching parameters.

\subsection{Reference case}

The reference case in Sennoune et al. [10] experiments corresponds to a steady high temperature combustion front. In this situation, all the initial calcium carbonate was decomposed. The composition is 3.475 (wt.\%) of fixed carbon and 22.45 (wt.\%) of calcium carbonate. The rest is considered to be inert solid. For other cases, the amount of fixed carbon and calcium carbonate are modified (as done also in the experiment). Effects on combustion front temperature, carbonate decomposition and so on were studied. Table 1 shows simulation input parameters for reference case and other cases.

\subsection{Reference case results}

The reference case experiment presented by Sennoune et al $[9,10]$ includes three repetitive tests. We conclude that 96.2 (wt.\%) of the fixed carbon was burned during the combustion. In our numerical model and based on the given kinetic model, all the fixed carbon consumes while high temperature front travels the porous medium.

Thus, according to Sennoune et al. [9,10], we fixed 96.2 (wt.\%) of initial fixed carbon content. The average value for $f r$ is 0.31 and is used for the simulation of reference case.

During experiments, all the injected oxygen was consumed and the mole fractions (average) of $\mathrm{CO}_{2}$ and $\mathrm{CO}$ in the exhaust gases were respectively 25.3 and 5.4. In our numerical experiments, all injected oxygen is reacting during the combustion and the compositions of exhaust gases were $29 \%$ and $6 \%$ respectively (for $\mathrm{CO}_{2}$ and $\mathrm{CO}$ respectively).

Combustion front velocity is $4.2 \mathrm{~mm} \mathrm{~min}^{-1}$ in the experiment. It is $4.3 \mathrm{~mm} \mathrm{~min}^{-1}$ according to the simulation.
The average peak temperature reported is $1032{ }^{\circ} \mathrm{C}$ while an average peak temperature of $930^{\circ} \mathrm{C}$ was found in the simulation. The factor that can influence the peak temperature is the heat losses. In reality the heat losses may not be linear as opposed to what we used in our model. As it will be presented in the next section (Fig. 5), for those cases at lower peak temperatures, the model reproduces the experimental temperatures in a satisfactory manner. This may suggest that this nonlinear effect is more important at higher temperatures, notably radiation heat losses at high temperatures become important. We may also consider the amount of initial carbon content (used in the simulation) that can influence the peak temperature. In the simulation, we have not introduced the same amount of carbon content as it was in the experiment but we multiplied it by a factor of 0.96 , which is the percentage of burned carbon. In a test simulation we used the same amount of fixed carbon as in the experiment, without multiplying by 0.96 . This resulted peak temperatures around $970{ }^{\circ} \mathrm{C}$ which is close to the experimental peak temperature. Thus it is also possible that the temperature difference (between $930{ }^{\circ} \mathrm{C}$ in the simulation and $1032{ }^{\circ} \mathrm{C}$ in the experiment) is due to the small experimental error in calculating the 0.96 factor for burned carbon.

We obtained the same amount (100\%) of calcium carbonate decomposition as it is measured in the experiment. This is what we expected, because mainly, the reaction is governed by the temperature values. In the front, we are above the reference temperature of $550{ }^{\circ} \mathrm{C}$ for carbonate decomposition.

Comparison of the experimental and numerical results shows that, in general, there is a good agreement between them. Small differences in the gas compositions compared to what was measured in the experiment may be explained by the fact that we used a simplified reaction scheme while in reality the process is more complex. Also our effective heat losses model is quite simplified; it can also explain why we do not achieve to obtain the correct values for temperature.

\subsection{Effect of porous medium composition}

In their experimental study, Sennoune et al. $[9,10]$ tried to reduce the front temperature during semi-coke combustion by changing the porous bed composition. The modifications of compositions in carbon content or calcium carbonate content can affect the combustion front temperature, but also front velocity, amount of decomposed carbonates and others. We also attempted to test our numerical tool by varying these two parameters and comparing the results with experimental observations.

\subsubsection{Fixed carbon content}

We simulated three cases with different initial fixed carbon content in the porous medium. This corresponds to cases number 2-4 in Table 1. In all cases we introduced a value for fr which was presented by Sennoune et al. $[9,10]$ based on the experimental results as indicated in Table 1. Fig. 5 shows the effect of fixed

Table 1

Simulation input parameters for different runs. Bold values are the parameters which have been changed in different tests.

\begin{tabular}{|c|c|c|c|c|c|c|c|}
\hline \multirow[t]{2}{*}{ Run } & \multirow{2}{*}{$\begin{array}{l}\text { Reference } \\
1\end{array}$} & \multicolumn{3}{|c|}{ Variation of fixed carbon } & \multicolumn{3}{|c|}{ Variation of calcium carbonate } \\
\hline & & 2 & 3 & 4 & 5 & 6 & 7 \\
\hline Bed density $\left(\mathrm{kg} \mathrm{m}^{-3}\right)$ & 1180 & 1190 & 1265 & 1290 & 1180 & 1180 & 1180 \\
\hline fr & 0.31 & 0.19 & 0.21 & 0.21 & 0.28 & 0.27 & 0.24 \\
\hline \multicolumn{8}{|l|}{ Bed composition (wt.\%) } \\
\hline Volatile material & 0.35 & 0.273 & 0.21 & 0.175 & 0.35 & & \\
\hline Fixed carbon & 3.475 & 2.71 & 2.085 & 1.73 & 3.475 & 3.475 & 3.475 \\
\hline $\mathrm{CaCO}_{3}$ & 22.41 & 22.41 & 22.41 & 22.41 & 32.41 & 42.41 & 72.41 \\
\hline Inert solid & 73.76 & 74.60 & 75.29 & 75.68 & 63.76 & 53.76 & 23.76 \\
\hline
\end{tabular}




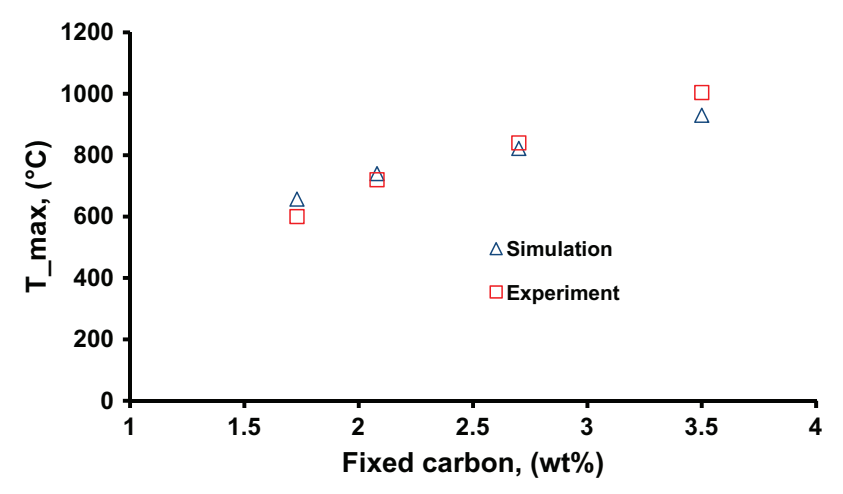

Fig. 5. Average peak temperature versus fixed carbon content. Comparison of experimental and numerical results.

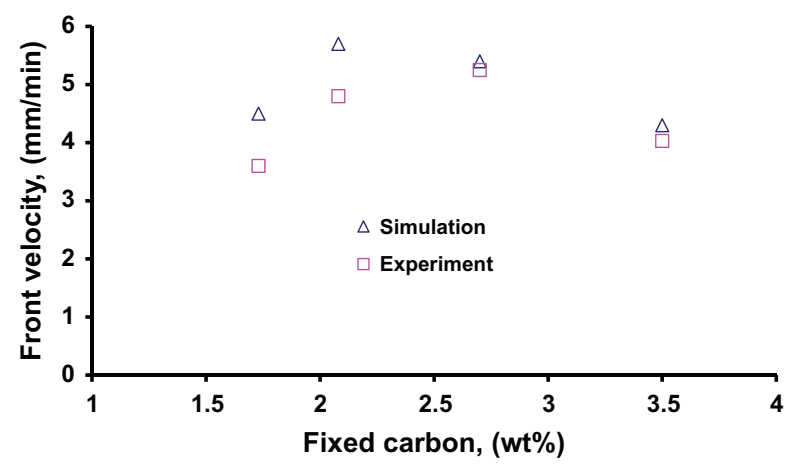

Fig. 6. Average front velocity versus fixed carbon content. Comparison of experimental and numerical results.

carbon content on peak temperature both in the experiment and simulation. The reference case is also added to this figure in order to allow better comparison and also to find trends. We see that the peak temperature decreases when we decrease the carbon content in the simulation as in the experiment. The predicted peak temperature for all cases (other than reference case at 3.475\%) shows a very good agreement with the experiment.

Fig. 6 indicates the comparison of combustion front velocity in the experiment and simulation as a function of carbon content. The general trend in both cases is the same. When we reduce the carbon content, the combustion front velocity increases which can be explained by considering the same oxygen availability. Thus, combustion front progresses faster in low carbon content cases compared to the higher one. But at still lower carbon content $(1.7 \%$ and $2.1 \%$, the velocity decreases. Sennoune et al. $[9,10]$ made three hypotheses:

(i) Firstly, because of temperature decrease, part of the injected oxygen cannot react with carbon, thus the front velocity decreases. In this situation the front velocity is related to the reaction kinetics. The presence of non-reacted oxygen in the exit gas can be clearly seen in Fig. 7A where the gas composition, in mole percent, is shown for different carbon content. Generally, there is a good agreement between experimental results and model predictions in this figure. Oxygen content in the exit gas flow is equal to zero for cases where front temperature is higher than $800^{\circ} \mathrm{C}$. Non-zero oxygen concentrations are observed for low carbon content and consequently for lower temperature combustion front.

(ii) Secondly, even with a well homogenized medium, some degree of heterogeneity remains. This may result the oxygen breakthrough. In addition, in a real world, there is always a
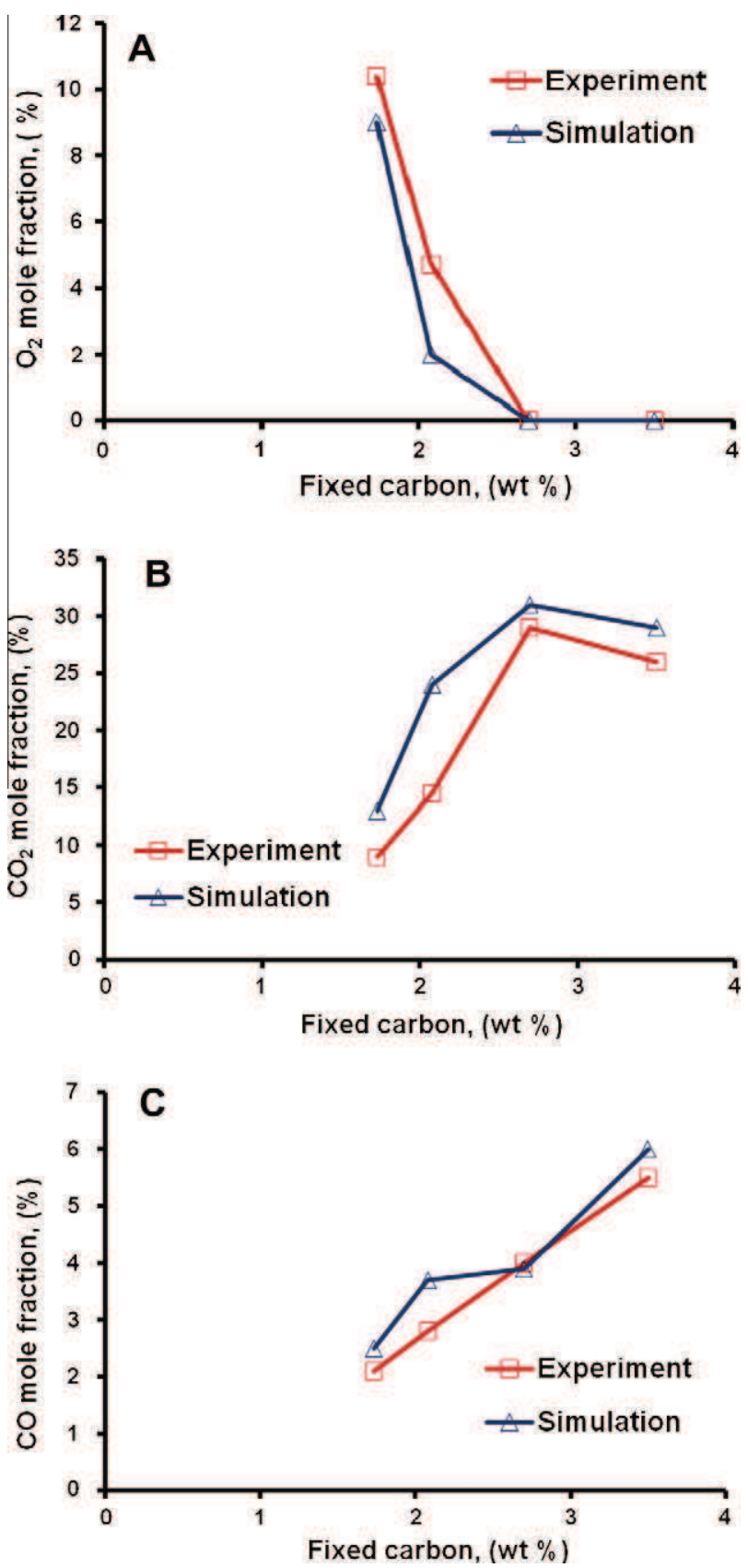

Fig. 7. Gas composition at the exit. Comparison of experimental and numerical results. A. oxygen, B. $\mathrm{CO}_{2}$ and C. $\mathrm{CO}$.

temperature gradient along the tube radius especially at combustion front position. This may also cause that oxygen penetrates ahead of the front in low temperature regions.

(iii) We may also mention a third element which is the channelling phenomenon and is well known in the chemical engineering domain. Channelling is the preferential passage of flow near the reactor wall, where the arrangement of the porous media is generally different from the bulk and more favourable for this passage. The area near the reactor wall has lower temperature compared to the center, thus oxygen may bypass the combustion front though this area [27].

In a one dimensional numerical model, none of the two last mentioned phenomenon (ii and iii) is present. There is no heterogeneity, no gradient in the radius axis and no channelling is 


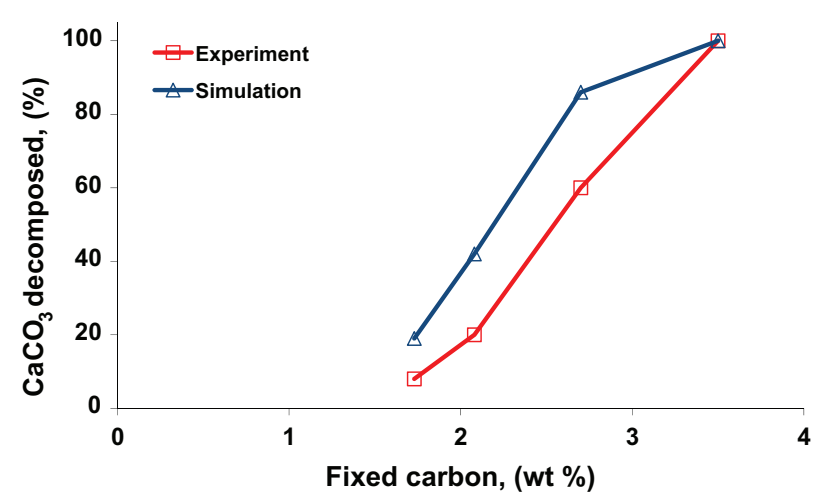

Fig. 8. Carbonate decomposition versus fixed carbon content. Comparison of experimental and numerical results.

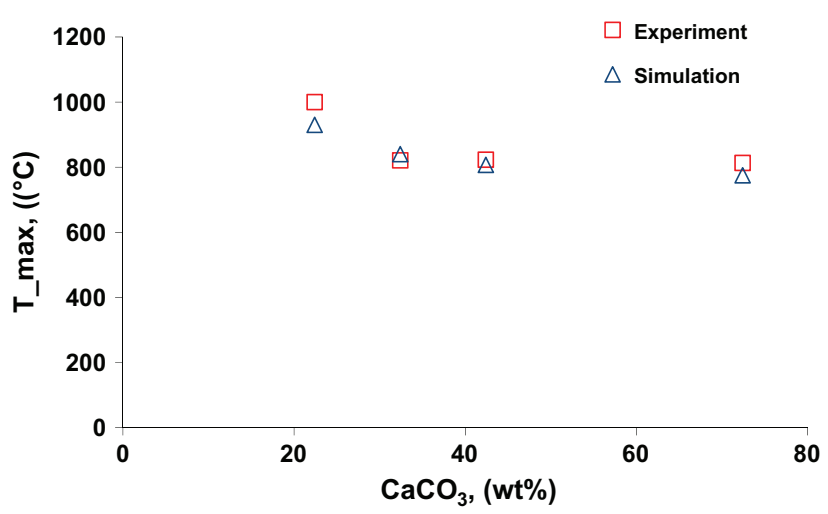

Fig. 9. Average peak temperature versus initial carbonate content. Comparison of experimental and numerical results.

present. The only reason that oxygen can pass through the front is due to low temperature condition. Under this situation, all of the available oxygen does not react with the carbon and part of the oxygen passes the combustion front without being reacted. Therefore, modelling of these experiments tends to validate the first hypothesis: low front temperature explain the non-zero $\mathrm{O}_{2}$ concentration at cell exit for low front temperature experiments.

Concentration of $\mathrm{CO}_{2}$ and $\mathrm{CO}$ at the exit gas is shown in Fig. 7B and $\mathrm{C}$. In overall, the model predicted the experimental data with a reasonable agreement. As we mentioned earlier, the combustion reaction in reality is not a single reaction but a combination of many different reactions. Considering that, these results show that a relatively simple reaction scheme is still able to produce reasonably accurate results.

The extent of carbonate decomposition for cases with different carbon content is shown in Fig. 8. Simulation results have the same tendency as the experimental ones. In both cases, the amount of decomposed calcium carbonate reduced when the carbon content reduces, i.e. with the temperature decrease. There is relatively a good agreement between experimental and numerical results. The discrepancy could be essentially due to the fact that a simple reaction scheme was used to describe carbonate decomposition, not taking into account the re-carbonation of $\mathrm{CaO}$ reaction $[28,29]$. Moreover, the impact of the $\mathrm{CO}_{2}$ local pressure on the kinetics of $\mathrm{CaCO}_{3}$ decomposition reaction was not taken into account.

\subsubsection{Effect of calcium carbonate content}

In another series of tests, we varied the calcium carbonate content to study the effects on combustion characteristics. Fig. 9

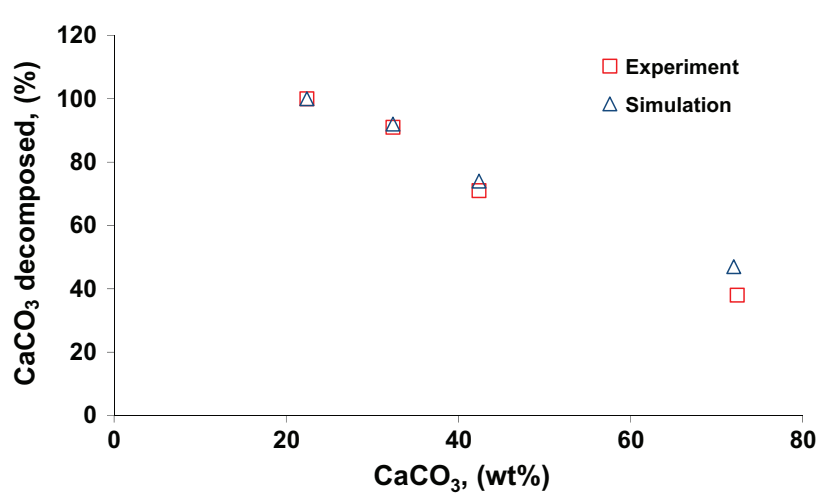

Fig. 10. Percentage of decomposed carbonate versus initial carbonate content. Comparison of experimental and numerical results.
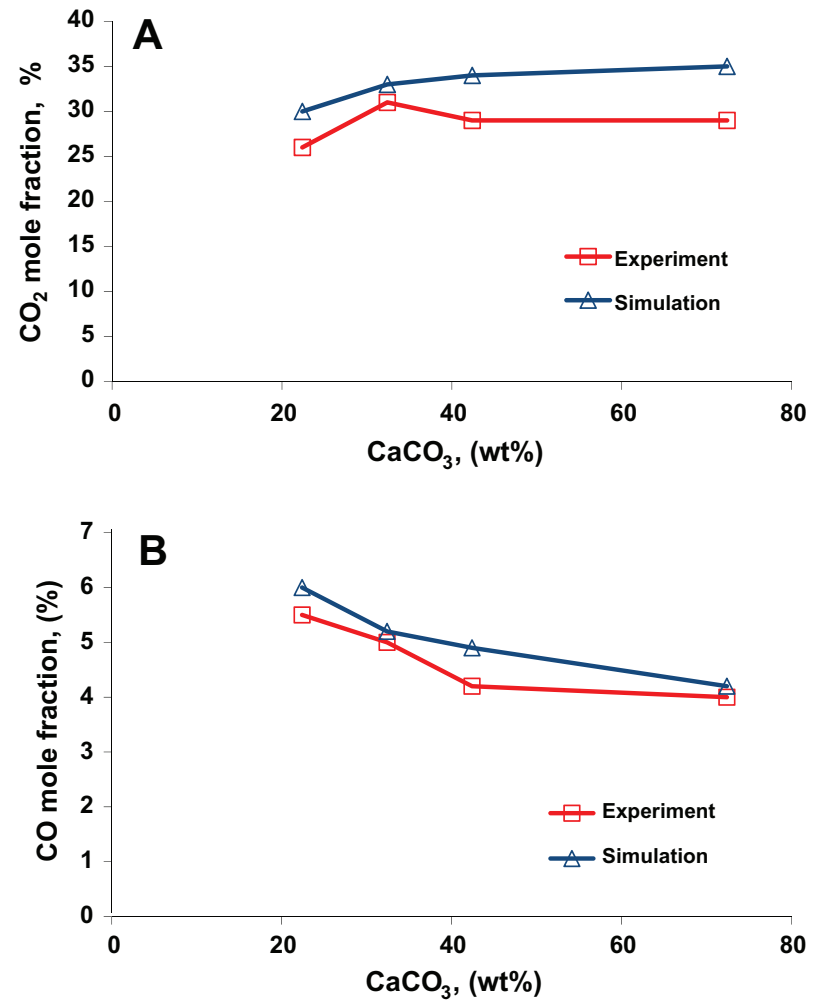

Fig. 11. Gas composition at the exit versus carbonate content. Comparison of experimental and numerical results. A. $\mathrm{CO}_{2}$ and B. $\mathrm{CO}$.

shows temperature versus carbonate content for three values of carbonate and also compared to the reference case. It indicates that, from $22.4 \%$ to $32 \%$ of carbonate content, the average peak temperature decreases and then remains constant when the percentage of carbonate is increased. Simulation results are in a fairly good agreement with experimental measurements.

More carbonate decomposition occurs in cases with higher carbonate content but there is a temperature limit (around $850^{\circ} \mathrm{C}$ ) below which the decomposition becomes limited. The percentage of decomposed carbonate as a function of initial carbonate content is presented in Fig. 10.

This figure clearly shows that for carbonate contents more than $42.4 \%$, the percentage of decomposed carbonate becomes less significant compared to the high decomposition percentage observed in cases with lower initial carbonate content. Another important aspect of calcium carbonate decomposition reaction is 
the dependency to $\mathrm{CO}_{2}$ partial pressure. This phenomenon may also play a role to limit the carbonate decomposition in experiments with high carbonate content. Our numerical model does not take into account this phenomenon and we will integrate it in our future model.

Fig. 11A and B shows the exit gas composition for different amounts of carbonate initially present in the system. There is a good match between experimental and numerical results. For all cases (including the reference case), oxygen concentration at the exit was zero (not shown in this figure) as it is also observed in the experimental study. $\mathrm{CO}_{2}$ concentration observed in the experiment increases when the carbonate content increases (compared to the reference case) and further increase in carbonate content results in slight decrease in the $\mathrm{CO}_{2}$ concentration. Simulation results indicate the same trend except that after initial increase in $\mathrm{CO}_{2}$ concentration, it remains relatively constant. Both of these results suggest that carbonate decomposition in samples with more than $32.4 \%$ of initial carbonate becomes limited.

The predicted CO concentration (Fig. 11B) is also in good agreement with the experimental results. Again, the small discrepancy may be related to the simplifications we made in reactions model used in our numerical tool.

\section{Conclusion}

A numerical study of filtration combustion in a porous bed containing fixed carbon and carbonates was successfully carried on in this work, and validated by comparison with several sets of experimental results. This success certainly lies on the fact that chemistry was simplified here by using a medium that did not contain organic matter other than fixed carbon, avoiding low temperature oxidation (LTO) and devolatilization reactions.

Using a simple reaction scheme for carbon oxidation into $\mathrm{CO}$ and $\mathrm{CO}_{2}$ required the experimental determination of the fraction of carbon that is oxidized to $\mathrm{CO}$. The present model cannot compute this determining parameter by itself; a perspective of this work is to establish and validate a more complex reaction scheme able to deal with this. The model is shown to catch the non-monotone evolution of the front velocity when varying the fixed carbon content of the medium, resulting from the non-utilization of all the fed oxygen when the front is too cold. In revenge, the model does not predict some residual carbon $(0.25 \mathrm{wt} . \%)$ after the passage of the front as observed in experiments.

Using a single reaction to describe carbonate decomposition not depending on the local $\mathrm{CO}_{2}$ partial pressure and not allowing re-carbonation of the formed $\mathrm{CaO}$ is shown to be an acceptable approach. The model can describe the partial decomposition of $\mathrm{CaCO}_{3}$ observed in several cases.

All together, a single set of kinetic parameters for each of the two reactions (fixed carbon oxidation and $\mathrm{CaCO}_{3}$ decomposition) is shown to describe satisfactorily all the sets of experimental results with different fixed carbon and carbonate contents.

The work in progress following these results is running the model in a 2D configuration, in order to evaluate its capacity to predict the experimentally observed front curvature resulting from heat losses at the cell walls.

\section{References}

[1] Sarathi PS. In-situ combustion handbook-principles and practices, Tulsa; 1999.

[2] Ohlemiller TJ. Modeling of smoldering combustion propagation. Prog Energy Combust Sci 1985;11:277-310.

[3] Oliveira M, Kaviany M. Nonequilibrium in the transport of heat and reactants in combustion in porous media. Prog Energy Combust Sci 2001;27:523-45.

[4] Matowsky B. Filtration combustion in smoldering and SHS. In: Sixth international microgravity combustion workshop, NASA Glenn Research Centre, Cleveland, OH, USA; 2001. p. 281-4.

[5] Aldushin AP, Merzhanov AG, Seplyarskii BS. Theory of filtration combustion of metals. Fiz Goren Vzryua 1976;12:323-8.

[6] Schult DA, Matkowsky BJ, Volpert VA. Forced forward smolder combustion. Eng Sci 1996;2180:1-26.

[7] Debenest Gerald, 3D, à la microéchelle, de la combustion en lit fixe de schistes bitumineux, Université de Poitiers, 2003.

[8] Elayeb M. Modélisation à l'échelle microscopique de transports avec réaction en milieu poreux: combustion en lit fixe, Université de Poitiers; 2008.

[9] Sennoune M, Salvador S, Quintard M. Reducing CO2 emissions from oil shale semicoke smoldering combustion by varying the carbonate and fixed carbon contents. Combust Flame 2011.

[10] Sennoune M, Salvador S, Debenest G, Mourzenko V. Mixing of an oil shale with inert or reactive media to avoid decarbonation at the passage of a combustion front. In: Canadian unconventional resources and international petroleum conference, Calgary, Alberta, Canada; 2010.

[11] Altun NE, Hiçyilmaz C, Hwang JY, Bağci AS. Oil shales in the world and turkey; reserves, current situation and future prospects: a review. Oil Shale 2006;23:211-27.

[12] Kok MV. Oil shale: pyrolysis, combustion, and environment: a review. Energy Sourc 2002;24:135-43.

[13] Kahru A, Põllumaa L. Environmental hazard of the waste streams of estonian oil shale industry: an ecotoxicological review. Oil Shale 2006:23:53-93.

[14] Külaots I, Goldfarb JL, Suuberg EM. Characterization of chinese, american and estonian oil shale semicokes and their sorptive potential. Fuel 2010;89:3300-6.

[15] Ots A. Oil shale combustion technology. Oil Shale 2004;21:149-60.

[16] Martins MF, Salvador S, Thovert J-F, Debenest G. Co-current combustion of oil shale - Part 1: Characterization of the solid and gaseous products. Fuel 2010;89:144-51.

[17] Martins MF, Salvador S, Thovert J-F, Debenest G. Co-current combustion of oil shale - Part 2: Structure of the combustion front. Fuel 2010;89:133-43.

[18] Manor HTY, Suuberg EM, Ho M. The Ignition and combustion behavior of spent shale particles. In: 19th Symp. (Int.) on Comb, The Combustion Institute; 1983. p. 1093-103.

[19] Martins MF. The structure of a combustion front propagating in a fixed bed of crushed oil shale: co-current configuration. Institut National Polytechnique de Toulouse; 2008.

[20] Whitaker S. The method of volume averaging (theory and applications of transport in porous media). Springer; 1999.

[21] Lapene A, Martins M, Debenest G, Quintard M, Salvador S. Numerical simulation of oil shale combustion in a fixed bed: modelling and chemical aspects. In: Eurotherm seminar No 81 reactive heat transfer in porous media, Albi, France; 2007.

[22] Elayeb M. Simulation of smouldering in reactive porous media using a four species/four reactions oxidation scheme. In: Eurotherm Seminar No 81 Reactive Heat Transfer in Porous Media, Albi, France; 2007.

[23] Criado J, Gonzalez M, Malek J, Ortega A. The effect of the $\mathrm{CO} 2$ presure on the thermal decomposition kinetics of calcium carbonateThe effect of the $\mathrm{CO} 2$ presure on the thermal decomposition kinetics of calcium carbonate. Thermochimica Acta 1995;254:121-7.

[24] Quintard M, Whitaker S. Local thermal equilibrium for transient heat conduction: theory and comparison with numerical experiment. Int J Heat Mass Transf 1995;38:2779-96.

[25] Smith E, Neavel C, Hippo EJ, Miller RN. DTGA combustion library of coals in the Exxon coal. Fuel 1981;60:458-62.

[26] Sanders JP, Gallagher PK. Kinetic analyses using simultaneous TG/DSC measurements Part I: decomposition of calcium carbonate in argon. Thermochimica Acta 2002;388.

[27] Lapene A, Debenest G, Quintard M, Martins MF, Salvador S. Heat and mass transport in a reactive porous medium: application to oil shales and heavy oil combustion. In: Aiche, Houston, TX, USA; 2007.

[28] Ingraham TR, Marier P. Kinetic studies on the thermal decomposition of calcium carbonate. Canadian J Chem Eng 1963;41:170-3.

[29] Rao TR, Gunn DJ, Bowen JH. Kinetics of calcium carbonate decomposition. Chem Eng Res Des 1989;67:38-47. 